\title{
Prenatal urban traffic noise exposure impairs spatial learning and memory and reduces glucocorticoid receptor expression in the hippocampus of male rat offspring
}

\author{
F.S. SAJJADI ${ }^{1}$, F. AGHIGHI ${ }^{1}$, Z. VAHIDINIA ${ }^{2}$, A. AZAMI-TAMEH ${ }^{2}$, \\ M. SALAMI ${ }^{1}$ and S.A. TALAEI ${ }^{*}$
}

\footnotetext{
${ }^{1}$ Physiology Research Center, Institute for Basic Sciences, Kashan University of Medical Sciences, Kashan, Islamic Republic of Iran

${ }^{2}$ Anatomical Sciences Research Center, Institute for Basic Sciences, Kashan University of Medical Sciences, Kashan, Islamic Republic of Iran
}

Received: July 28, 2019 • Accepted: March 11, 2020

Published online: July 24, 2020

(c) 2020 Akadémiai Kiadó, Budapest.

\begin{abstract}
Introduction: Exposure to noise stress during early life may permanently affect the structure and function of the central nervous system. The aim of this study was to evaluate the effects of prenatal exposure to urban traffic noise on the spatial learning and memory of the rats' offspring and the expression of glucocorticoid receptors (GRs) in their hippocampi. Methods: Three g|roups of pregnant rats were exposed to recorded urban traffic noise for 1, 2 or $4 \mathrm{~h}$ /day during the last week of pregnancy. At the age of 45 days, their male offspring were introduced to the Morris water maze (MWM) for assessment of spatial learning and memory. The corticosterone levels were measured in the offspring's sera by radioimmunoassay, and the relative expression of glucocorticoid and mineralocorticoid receptors (MRs) in their hippocampi was evaluated via RT-PCR. Results: Facing urban traffic noise for 2 and 4 h/day during the third trimester of pregnancy caused the offspring to spend more time and to travel a larger distance than the controls to find the target platform. Analogously, these two groups were inferior to their control counterparts in the probe test. Also, prenatal noise stress elevated the corticosterone concentration in the sera of the rats' offspring and dose-dependently decreased the relative expression of the mRNA of both GRs and MRs in their hippocampi. Conclusions: Urban traffic noise exposure during the last trimester of pregnancy impairs spatial learning and memory of rat offspring and reduces GRs and MRs gene expression in the hippocampus.
\end{abstract}

* Corresponding author: Physiology Research Center, Kashan University of Medical Sciences, Qotb-e Ravandi, Kashan, Islamic Republic of Iran. Tel.: +98 9133623240; fax: +98 3155621157, E-mail: talaei@kaums.ac.ir 


\section{KEYWORDS}

noise, stress, prenatal period, glucocorticoid receptor, spatial learning and memory, hippocampus

\section{INTRODUCTION}

In modern cities, exposure to potentially risky noise levels is unavoidable. This important stressor might be responsible for several disorders that affect all body systems, especially the nervous system [1]. Several studies suggest that noise stress can induce a number of symptoms, including emotional disorders, anxiety and learning and memory impairments in humans and laboratory animal models [2]. Stress activates the hypothalamus-pituitary-adrenal (HPA) axis, which results in the release of corticosterone from the adrenal cortex of rodents. Corticosterone can easily pass the blood-brain barrier and bind to the specific receptors, the mineralocorticoid receptors (MRs) and the glucocorticoid receptors (GRs) [3]. These two receptors have a high concentration and distinct distribution in the hippocampus, a brain region that is involved in spatial learning and memory [4]. Both GRs play an important role in hippocampal-dependent learning and memory and also in the maintenance of hippocampal synaptic plasticity [5] as a cellular model of memory formation. The effects of GRs and MRs on learning and memory have been the subject of controversies [6]. On one hand, several studies have revealed that GRs and MRs are required for learning tasks and memory consolidation [7] and, on the other hand, there are several research reports indicating that GRs' and MRs' activation impairs learning and memory [8].

Pregnancy can be considered as a stressor that increases the level of glucocorticoids in the mother's plasma. Glucocorticoids can reach the fetal plasma via placenta, but their concentrations remain much lower than in the mother [9], because about $80 \%$ is metabolized by 11-beta hydroxysteroid dehydrogenase (11 $\beta$-HSD) in the placenta into inactive metabolites [10]. It has been shown that prolonged maternal stress epigenetically inactivates $11 \beta$-HSD, resulting in exposure of the fetus to high levels of glucocorticoids [11]. In addition, in the late pregnancy, the fetus can hear sounds from outside the mother [12], and since during the early life period development of mammals is influenced by both genetic codes and environmental factors [13], exposure to any stress can affect the programming and development of the fetal nervous system [14]. Several studies have confirmed that prenatal and early postnatal stress changes the structure and morphology of the hippocampal region, which results in long-lasting impairment of hippocampal synaptic plasticity and hippocampal-dependent learning and memory $[8,15,16]$.

In this study, we investigated the effects of prenatal exposure to urban traffic noise on the spatial learning and memory of rat offspring and the expression of GRs in their hippocampi.

\section{MATERIAL AND METHODS}

\section{Animals, noise exposure and grouping}

Twenty female (180-200 g) and 10 male Wistar rats (250-280 g) were used as parents. For mating, two virgin females were randomly selected and housed in the presence of a sexually 
experienced male in each standard animal cage. Vaginal smears were obtained each morning to detect mating. The pregnant animals were individually housed with free access to standard food and water in a temperature-controlled $\left(22 \pm 2{ }^{\circ} \mathrm{C}\right)$ animal room, on a $12 \mathrm{~h} \mathrm{light/dark} \mathrm{cycle.} \mathrm{All}$ experiments were carried out in accordance with Directive 2010/63/EU on the protection of animals used for scientific purposes and approved by the Ethical Committee of Kashan University of Medical Sciences, Kashan, Iran (1392.4968). The pregnant dams were assigned randomly to control $(\mathrm{n}=5)$ and three stress groups $(\mathrm{n}=5$ for each group). Broadband traffic noise used in this study was recorded by a standard recorder (Panasonic RQ-L11) in a hightraffic square of Tehran and was amplified by a loudspeaker (Power $56 \mathrm{~W}$ ) placed at $30 \mathrm{~cm}$ above the pregnant rat's cage (one rat per cage) in a Plexiglas chamber $(25 \times 35 \times 70 \mathrm{~cm})$. The amplitude of the recorded noise was set at $95 \mathrm{~dB}$ by software (Sonar, Cakewalk, USA), and the noise level was measured with a sound level meter (Extech Instruments, MA; USA) during the experiments. Stress group animals were exposed to the noise (1, 2 and $4 \mathrm{~h}(\mathrm{~s})$ per day during the last week of pregnancy) between 08:00 to 14:00 daily. Control animals were kept in the noise chamber, but without being exposed to noise. After parturition and weaning only, two male offspring from each dam in each experimental group were randomly selected and kept till the age of 7 weeks, i.e. when the rats' brain is matured $[17,18]$. These offspring groups $(n=10)$ were subjected to the following experiments.

\section{Spatial learning and memory}

Spatial learning and memory were examined by Morris water maze (MWM) on four consecutive days with four trials/day [19]. MWM was a black circular metal tank $(150 \mathrm{~cm}$ in diameter and $70 \mathrm{~cm}$ in depth) that was filled with water $\left(22^{\circ} \mathrm{C}\right)$ up to $20 \mathrm{~cm}$ below the rim. A circular platform (10 cm in diameter) was located $2 \mathrm{~cm}$ below the water surface and in the centre of one arbitrarily selected quadrant. The animal's navigation was monitored by video camera and tracking software (Radiab 7.1, Nomirei Co., Iran). The rats were permitted to swim for a maximum time of $60 \mathrm{~s}$ to find the hidden platform. If the rat could not find the platform, it was guided onto the platform manually. After a 15-min interval the rat was again placed in the pool at a different starting point. The time spent and the distance traveled to find the hidden platform during each trial were measured as indices of the learning of the spatial task. After completing the learning trials, the probe trial test was also done. The platform was removed from the pool, and the rats were placed in the quadrant opposite to the platform (target) quadrant and allowed to swim freely for $30 \mathrm{~s}$. The time elapsed and the distance traveled in the target quadrant were recorded as spatial memory.

\section{Hippocampus extraction and RT-PCR}

After completing the MWM test, all animals were fully anesthetized with Ketamine $(100 \mathrm{mg} / \mathrm{kg}$, i.p.). Blood samples were taken from their tail veins and then they were sacrificed by decapitation. Their brains were removed rapidly, and their hippocampi were dissected quickly and placed in RNA stabilization reagent (Qiagen, Germany) overnight at $4{ }^{\circ} \mathrm{C}$ and finally stored at $-80{ }^{\circ} \mathrm{C}$ until used. Total RNA was isolated from tissues by extraction with Trizol (Invitrogen, Paisley, UK) and using the RNeasy Mini Spin Columns Collection Tubes (Qiagen, Germany). Reverse transcription was done using RT-PCR according to the manual's instructions (High Capacity cDNA Reverse Transcription Kits, USA). Using specific primer sets (Table 1), aliquots 
Table 1. Primers used for RT-PCR

\begin{tabular}{|c|c|c|c|}
\hline Genes & $\begin{array}{l}\text { Product } \\
\text { size (bp) }\end{array}$ & $\begin{array}{c}\text { Annealing } \\
\text { temperature }\left({ }^{\circ} \mathrm{C}\right)\end{array}$ & Sequences \\
\hline GR1 (GR) & 164 & 60.4 & $\begin{array}{l}\text { F: } 5^{\prime} \text {-ctaattccccacctcccatt- } 3^{\prime} \\
\text { R: } 5^{\prime} \text {-gaggctgcatgggaaaata- } 3^{\prime}\end{array}$ \\
\hline GR2 (MR) & 206 & 62.1 & $\begin{array}{l}\text { F: } 5^{\prime} \text {-ggtcacaggtcctccacact- } 3^{\prime} \\
\text { R: } 5^{\prime} \text {-ggaggaggacatggagttga- } 3^{\prime}\end{array}$ \\
\hline HPRT (Housekeeper) & 125 & 60 & $\begin{array}{l}\text { F: } 5^{\prime} \text {-caatcaagacgttctttccagt- } 3^{\prime} \\
\text { R: } 5^{\prime} \text {-ggtccattcctatgactgtagatttt- } 3^{\prime}\end{array}$ \\
\hline
\end{tabular}

of cDNA were amplified by a PCR machine (Peqlab, Germany), with initial denaturation at $94{ }^{\circ} \mathrm{C}$ for $5 \mathrm{~min}$, followed by 33 cycles of denaturation at $94{ }^{\circ} \mathrm{C}$ for $45 \mathrm{~s}$, annealing at various primer-specific temperatures for $45 \mathrm{~s}, 1 \mathrm{~min}$ for extension at $72{ }^{\circ} \mathrm{C}$, and a further 5 -min final extension at $72{ }^{\circ} \mathrm{C}$ on completion of the cycles. The amplified products were subjected to electrophoresis in $2 \%(\mathrm{~W} / \mathrm{V})$ agarose gel, stained with ethidium bromide, then observed and photographed under an ultraviolet lamp in a gel imaging system. PCR product bands were analyzed with the ImageJ 2.2 software (National Health Institute, USA); the ratio of each target gene to the house-keeping gene hypoxanthine-guanine phosphoribosyl transferase (HPRT) was taken as the semi-quantitative result of the sample.

\section{Corticosterone assay}

Corticosterone levels of adult rat offspring were measured in blood samples drawn from the tail vein. Blood corticosterone levels were determined by radioimmunoassay (RIA) using a kit (DRG, Germany). Assays were conducted according to the protocols provided by the manufacturer.

\section{Statistical analysis}

The data are expressed as means \pm SEM. Two-way analysis of variance (ANOVA) was performed on the spatial learning data. The probe trial, RT-PCR, and corticosterone assay data were analyzed with one-way ANOVA. Tukey's test was applied as post hoc. All statistical analysis was done with SPSS 20 software and $P<0.05$ was considered as significant difference.

\section{RESULTS}

\section{Prenatal noise stress impairs spatial learning and memory in male offspring}

The male offspring were introduced to MWM for 4 days to find a fixed hidden platform in one quarter of the maze. Analysis of the data by two-way ANOVA showed a significant difference among groups of the study concerning the time spent and the distance traveled during the water maze navigation. The offspring of the rats that faced urban traffic noise for 2 and $4 \mathrm{~h}$ /day during the third trimester of pregnancy spent more time $(P<0.01$ for both comparisons $)$ and traveled larger distance $(P<0.01$ and $P<0.001$, respectively) to find the hidden platform during 4 days 

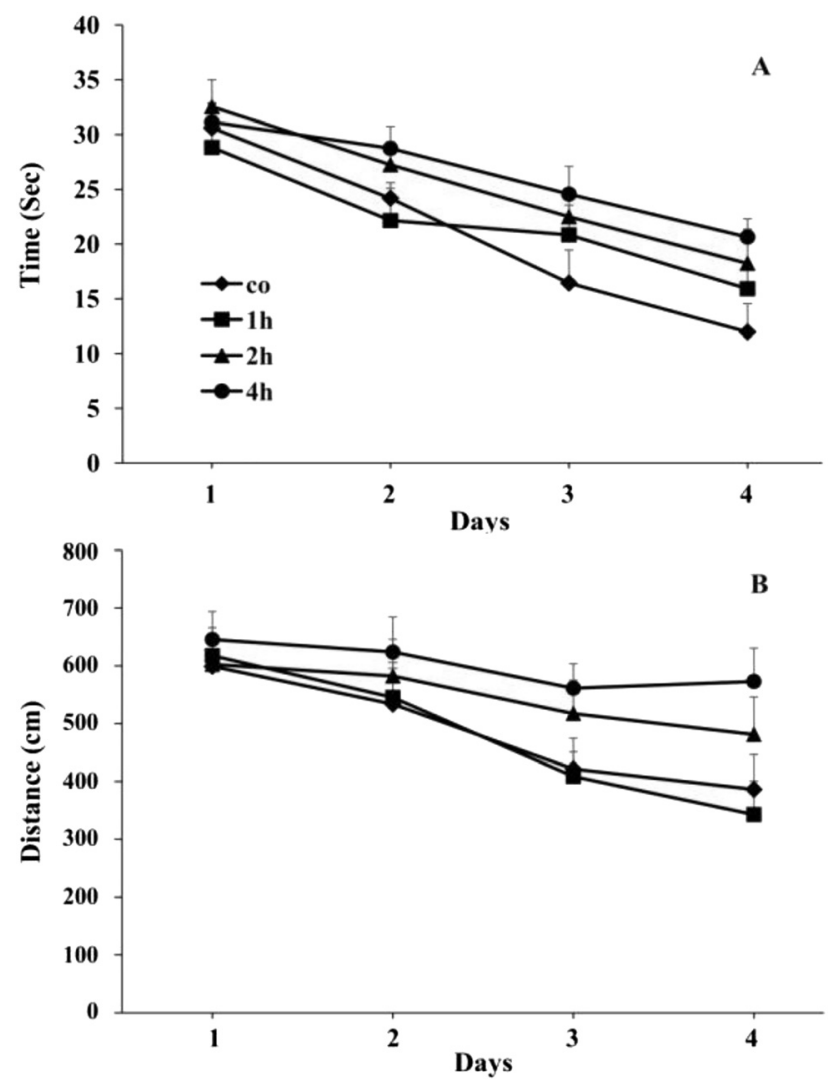

Fig. 1. Prenatal noise stress impaired spatial learning of male rats in the MWM. Facing urban traffic noise for 2 and $4 \mathrm{~h}$ /day during the third trimester of pregnancy caused the male offspring to spend more time ( $P$ $<0.01$ for both comparisons) (A) and to travel more distance $(P<0.01$ and $P<0.001$, respectively) (B) than the controls to find the target platform

of maze learning compared to the control group (CO) (Fig. 1A and B). Also, the rats in the 2 and 4 h groups spent significantly less time $(P<0.01$ and $P<0.001$, respectively $)$ and traveled less distance $(P<0.01$ for both comparisons) in the target quadrant of maze during probe trial compared to the $\mathrm{CO}$ animals (Fig. $2 \mathrm{~A}$ and $\mathrm{B}$ ), which showed that prenatal noise stress causes impairment of the spatial memory of rats.

\section{Prenatal noise stress decreases the expression of glucocorticoid receptor (GR) mRNA in the hippocampi of male offspring}

Using the RT-PCR technique, the relative expression of the mRNAs of two glucocorticoid receptors (GR1 and GR2) was measured in the hippocampi of rats. Data analysis by one-way ANOVA revealed a significant difference in relative expression of the mRNAs among all groups of the study. Fig. 3A demonstrates that the relative mRNA expression of the GR1 receptor 



Fig. 2. Prenatal noise stress impaired spatial memory of male rat offspring in the MWM. The rats in the 2 and $4 \mathrm{~h}$ groups spent significantly less time $(P<0.01$ and $P<0.001$, respectively) (A) and traveled less distance $(P<0.01$ for both comparisons) $(\mathrm{B})$ in the target quadrant of the maze during probe trial compared to the $\mathrm{CO}$ animals

decreased from $0.97 \pm 0.02$ in the hippocampi of $\mathrm{CO}$ rats to $0.74 \pm 0.03,0.48 \pm 0.04$ and $0.43 \pm$ 0.04 in the 1,2 and $4 \mathrm{~h}$ animals, respectively ( $P<0.001$ for all comparisons). The results of Tukey's test showed that exposition to traffic noise during pregnancy causes a significant decrease in the relative expression of the mRNA of the GR2 receptor in the hippocampi of of the rats' offspring: while it was $1.15 \pm 0.08$ in the CO group, it decreased to $0.88 \pm 0.02,0.78 \pm 0.06$ and $0.71 \pm 0.09$ in the 1,2 and $4 \mathrm{~h}$ animals, respectively $(P<0.001$ for all comparisons) (Fig. 3B).

\section{Prenatal noise stress elevates corticosterone levels of the serum in male offspring}

Corticosterone concentration in the sera of the rats' offspring was measured by RIA method. As shown in Fig. 4, facing urban traffic noise during the last week of pregnancy significantly elevates the corticosterone levels in the sera of the rats' offspring. The corticosterone level in the sera of CO rats was $192.23 \pm 21.72 \mathrm{ng} / \mathrm{mL}$ and increased by about $30(P<0.01), 100(P<0.001)$ and $150(P<0.001)$ percent in the 1,2 and $4 \mathrm{~h}$ rats, respectively. 

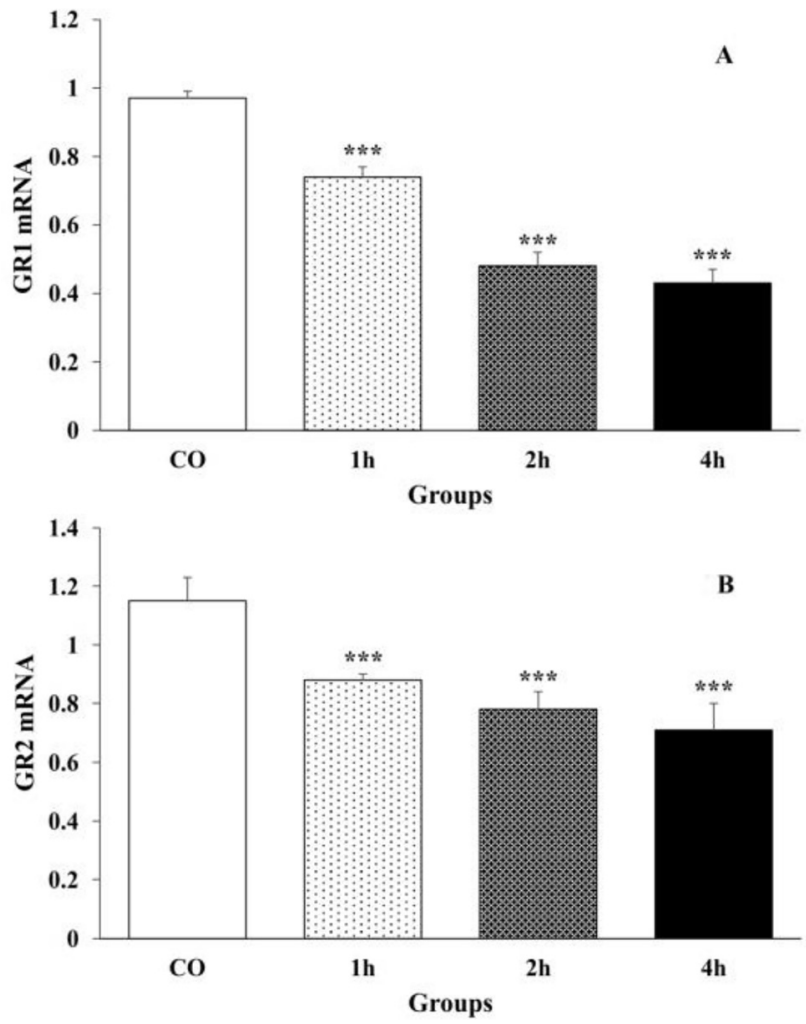

Fig. 3. Prenatal noise stress decreased relative expression of mRNA of both glucocorticoid receptors in the hippocampi of male rat offspring. Encountering urban traffic noise for 1, 2 and $4 \mathrm{~h}$ /day during the third trimester of pregnancy significantly diminished the relative expression of GR1 (A) and GR2 (B) genes as compared to the control ${ }^{\star * *} P<0.001$ for all comparisons)

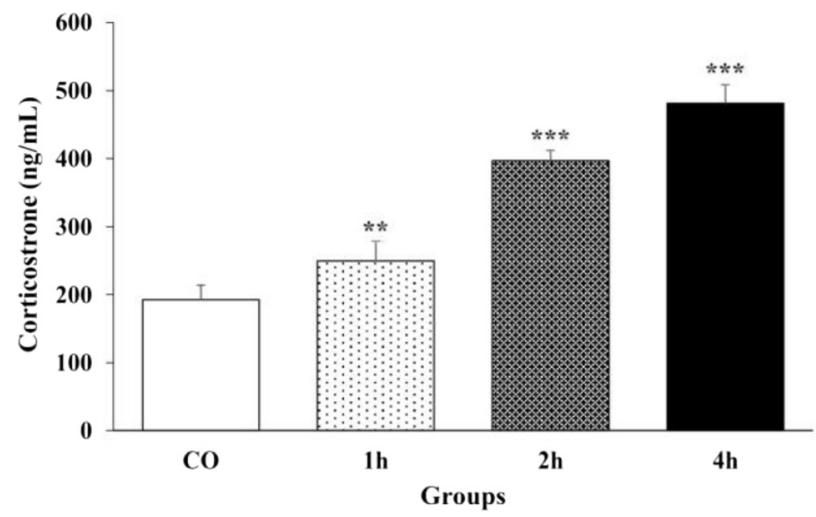

Fig. 4. Facing urban traffic noise for 1, 2 and $4 \mathrm{~h}$ /day during the third week of pregnancy time-dependently elevated corticosterone concentration in the sera of male rat offspring. ${ }^{* *} P<0.01$ vs. $\mathrm{CO}$ and ${ }^{* *} P<0.001$ vs. CO. 


\section{DISCUSSION}

The results of this study show that facing urban traffic noise during the last week of pregnancy impairs spatial learning and memory of the rats' offspring in MWM, and also increases serum corticosterone levels and decreases the expression of both GRs and MRs genes in their hippocampi.

The negative impact of stress on learning and memory is proposed to be modulated by various mechanisms, possibly by involving glucocorticoids [20]. Studies have frequently shown that noise stress significantly enhances the release of glucocorticoids, which leads to damages in learning and memory [21, 22]. In agreement with other studies [9], we previously demonstrated that pregnancy itself increases serum corticosterone and facing, in addition, urban traffic noise stress during pregnancy enhances this increase [21]. It has been shown that elevated corticosterone in pregnant rats inactivates $11 \beta$-HSD in the placenta and finally results in exposure of the fetus to high levels of glucocorticoids [11]. Besides, in late pregnancy, the fetus can hear sounds from outside the mother [12], and noise stress may increase the corticosterone in fetal serum directly. Thus, in other words, facing noise stress during pregnancy elevates corticosterone levels in both mother and fetus [23]. In mammals, during the prenatal period of development both genetic codes and environmental factors affect the Central nervous system (CNS) [13], and exposure to any stress permanently affects the programming and development of the fetal nervous system [14]. There are several studies showing that prenatal stress including noise stress [24, 25] changes the neuronal structure of the hippocampus including a decrease in neurogenesis, changes in neurochemistry, excitability, and dendritic morphology, and also an increase in cell death which leads to impairment of learning and memory [26]. For example, prenatal stress caused a significant reduction in the volume of the CA3 region and also a reduction in the number of cells in the CA1 and CA3 regions of the hippocampi of male offspring [15]. Morales-Medina et al. has revealed that administration of corticosterone causes dendritic remodeling and spine density reorganization in the CA1 area of rat hippocampus [27]. Also, it has been demonstrated that the mother-infant relationship deeply affects the pups' development and behavior [28]. Although some studies have proposed that prenatal stress does not alter maternal behavior [29], there are studies indicating that prenatal stress alters dam-pup relationship such as maternal nesting, nursing, retrieval behavior, and also increases cannibalism [30]. In this experimental study, we checked miscarriage and the nursing behavior of rats and we did not see any obvious differences between the control and stressed mothers. This is probably the result of pregnant rats' adaptation to the noisy situation during the experiment, or actually due to the ineffectiveness of sound stress on pregnant rats' behavior. However, for a clear answer we suggest a cross fostering study in future experiments.

Under normal conditions, glucocorticoids and their receptors are necessary for memory formation. The GR and MR mRNAs are present in the hippocampus of rats by gestational days 13-16 [31]. These hormones affect learning and memory via interaction with the glutamatergic system. Activation of pre-synaptically-located MRs in the hippocampus increases glutamate release, and activation of post-synaptically-located GRs induces the synaptic delivery of $\alpha$-amino-3-hydroxy-5-methyl-4-isoxazolepropionic acid (AMPA) receptors that facilitates memory formation [32]. Similarly, it has been shown that the blockade of both MRs and GRs impairs both the reference and working memory of rats in a spatial learning paradigm [33]. Recently, a team of researchers has demonstrated that genetic disruption of GRs in the lateral 
amygdala resulted in fear memory deficit. Also, they have shown that prior stress suppresses fear conditioning-induced Long-term potentiation (LTP) at auditory inputs to the lateral amygdala in a GR-dependent manner [34]. Moreover, the genetic deletion of MRs in the forebrain resulted in impaired learning in a Morris water-maze task [35]. In addition, the level of expression of the GRs is determined by glucocorticoids in a tissue-specific manner in response to the prenatal environment, with glucocorticoids downregulating the receptors' mRNA in most cells and tissues [36]. In line with our results, in one study rats were stressed in restrainer during the last week of pregnancy. The density of GRs in the hippocampi of their female offspring was 50 percent lower than in those of the non-stressed offspring [37]. Mifsud et al. have reported that only 15 minutes forced swim stress downregulates GRs in the hippocampi of rats [38]. Also, it has been shown that synthetic glucocorticoid administration to the fetus [39] or prenatal stress [40] leads to downregulation of GRs in the hippocampus and an increase in HPA responsiveness that might be reasons for changes in the stress-induced behavior of the offspring [41].

\section{CONCLUSION}

In conclusion, urban traffic noise exposure during the last trimester of pregnancy impairs spatial learning and memory of rats' offspring and reduces the GRs and MRs gene expression in the hippocampus.

Conflicts of interest: The authors declare that they have no conflicts of interest to disclose.

\section{ACKNOWLEDGMENT}

This research project was financially supported by grant no. 92136, Deputy of Research and Technology, Kashan University of Medical Sciences, Kashan, Iran. We would like to thank Dr Gh. Hamidi for his technical assistance.

\section{REFERENCES}

1. Kozlowska L, Gromadzinska J, Wasowicz W. Health risk in transport workers. Part II. Dietary compounds as modulators of occupational exposure to chemicals. Int J Occup Med Environ Health 2019; 32: 441-64.

2. Jafari Z, Kolb BE, Mohajerani MH. Noise exposure accelerates the risk of cognitive impairment and Alzheimer's disease: Adulthood, gestational, and prenatal mechanistic evidence from animal studies. Neurosci Biobehav Rev 2019. S0149-7634(18)30897-2.

3. Meijer OC, Buurstede JC, Schaaf MJM. Corticosteroid receptors in the brain: transcriptional mechanisms for specificity and context-dependent effects. Cell Mol Neurobiol 2019; 39: 539-49.

4. Viho EMG, Buurstede JC, Mahfouz A, Koorneef LL, van Weert L, Houtman R, et al. Corticosteroid action in the brain: the potential of selective receptor modulation. Neuroendocrinology 2019; 109: 266-76.

5. Korz V, Frey JU. Stress-related modulation of hippocampal long-term potentiation in rats: involvement of adrenal steroid receptors. J Neurosci 2003; 23: 7281-7. 
6. Madalena KM, Lerch JK. The effect of glucocorticoid and glucocorticoid receptor interactions on brain, spinal cord, and glial cell plasticity. Neural Plast 2017; 2017: 8640970.

7. Tertil M, Skupio U, Barut J, Dubovyk V, Wawrzczak-Bargiela A, Soltys Z, et al. Glucocorticoid receptor signaling in astrocytes is required for aversive memory formation. Transl Psychiatry 2018; 8: 255.

8. Schwabe L, Joels M, Roozendaal B, Wolf OT, Oitzl MS. Stress effects on memory: an update and integration. Neurosci Biobehav Rev 2012; 36: 1740-9.

9. Gitau R, Fisk NM, Teixeira JM, Cameron A, Glover V. Fetal hypothalamic-pituitary-adrenal stress responses to invasive procedures are independent of maternal responses. J Clin Endocrinol Metab 2001; 86: 104-9.

10. Benediktsson R, Calder AA, Edwards CR, Seckl JR. Placental 11 beta-hydroxysteroid dehydrogenase: a key regulator of fetal glucocorticoid exposure. Clin Endocrinol (Oxf) 1997; 46: 161-6.

11. Jensen Peña C, Monk C. Champagne FA: Epigenetic effects of prenatal stress on 11 $\beta$-hydroxysteroid dehydrogenase-2 in the placenta and fetal brain. PLOS One 2012; 7: e39791.

12. Querleu D, Renard X, Versyp F, Paris-Delrue L, Crèpin G. Fetal hearing. Eur J Obstet Gynecol Reprod Biol 1988; 28: 191-212.

13. Alyamani RAS, Murgatroyd C. Epigenetic programming by early-life stress. Prog Mol Biol Transl Sci 2018; 157: 133-50.

14. Jafari Z, Mehla J, Kolb BE, Mohajerani MH. Prenatal noise stress impairs HPA axis and cognitive performance in mice. Sci Rep 2017; 7: 10560.

15. Soares-Cunha C, Coimbra B, Borges S, Domingues AV, Silva D, Sousa N, et al. Mild prenatal stress causes emotional and brain structural modifications in rats of both sexes. Front Behav Neurosci 2018; 12: 129.

16. Weinstock M. The long-term behavioural consequences of prenatal stress. Neurosci. Biobehav Rev 2008; 32: 1073-86.

17. Calabrese E, Badea A, Watson C, Johnson GA. A quantitative magnetic resonance histology atlas of postnatal rat brain development with regional estimates of growth and variability. NeuroImage 2013; 71: 196-206.

18. Yang L, Pan Z, Zhou L, Lin S, Wu K. Continuously changed genes during postnatal periods in rat visual cortex. Neurosci Lett 2009; 462: 162-5.

19. Arbabi E, Hamidi G, Talaei SA, Salami M. Estrogen agonist genistein differentially influences the cognitive and motor disorders in an ovariectomized animal model of Parkinsonism. Iran J Basic Med Sci 2016; 19: 1285-90.

20. Sandi C, Pinelo-Nava MT. Stress and memory: behavioral effects and neurobiological mechanisms. Neural Plast 2007; 2007: 78970.

21. Barzegar M, Sajjadi FS, Talaei SA, Hamidi G, Salami M. Prenatal exposure to noise stress: anxiety, impaired spatial memory, and deteriorated hippocampal plasticity in postnatal life. Hippocampus 2015; 25: 187-96.

22. Hu L, Yang J, Song T, Hou N, Liu Y, Zhao X, et al. A new stress model, a scream sound, alters learning and monoamine levels in rat brain. Physiol Behav 2014; 123: 105-13.

23. Weinstock M. Prenatal stressors in rodents: Effects on behavior. Neurobiol Stress 2016; 6: 3-13.

24. Gonzalez-Perez O, Chavez-Casillas O, Jauregui-Huerta F, Lopez-Virgen V, Guzman-Muniz J, Moy-Lopez N, et al. Stress by noise produces differential effects on the proliferation rate of radial astrocytes and survival of neuroblasts in the adult subgranular zone. Neurosci Res 2011; 70: 243-50.

25. Liu L, Shen P, He T, Chang Y, Shi L, Tao S, et al. Noise induced hearing loss impairs spatial learning/memory and hippocampal neurogenesis in mice. Sci Rep 2016; 6: 20374.

26. Weinstock M. Sex-dependent changes induced by prenatal stress in cortical and hippocampal morphology and behaviour in rats: an update. Stress 2011; 14: 604-13.

27. Morales-Medina JC, Sanchez F, Flores G, Dumont Y, Quirion R. Morphological reorganization after repeated corticosterone administration in the hippocampus, nucleus accumbens and amygdala in the rat. J Chem Neuroanat 2009; 38: 266-72. 
28. Perez-Laso C, Ortega E, Martin JL, Perez-Izquierdo MA, Gomez F, Segovia S, et al. Maternal care interacts with prenatal stress in altering sexual dimorphism in male rats. Horm Behav 2013; 64: 624-33.

29. Pardon M, Gerardin P, Joubert C, Perez-Diaz F, Cohen-Salmon C. Influence of prepartum chronic ultramild stress on maternal pup care behavior in mice. Biol Psychiatry 2000; 47: 858-63.

30. Patin V, Lordi B, Vincent A, Thoumas JL, Vaudry H, Caston J. Effects of prenatal stress on maternal behavior in the rat. Brain Res Dev Brain Res 2002; 139: 1-8.

31. Diaz R, Brown RW, Seckl JR. Distinct ontogeny of glucocorticoid and mineralocorticoid receptor and 11 betahydroxysteroid dehydrogenase types I and II mRNAs in the fetal rat brain suggest a complex control of glucocorticoid actions. J Neurosci 1998; 18: 2570-80.

32. Sandi C. Glucocorticoids act on glutamatergic pathways to affect memory processes. Trends Neurosci 2011; 34: $165-76$.

33. Douma BRK, Korte SM, Buwalda B, la Fleur SE, Bohus B, Luiten PGM. Repeated blockade of mineralocorticoid receptors, but not of glucocorticoid receptors impairs food rewarded spatial learning. Psychoneuroendocrinology 1998; 23: 33-44.

34. Inoue R, Abdou K, Hayashi-Tanaka A, Muramatsu SI, Mino K, Inokuchi K, et al. Glucocorticoid receptormediated amygdalar metaplasticity underlies adaptive modulation of fear memory by stress. Elife 2018; 7: e34135.

35. Berger S, Wolfer DP, Selbach O, Alter H, Erdmann G, Reichardt HM, et al. Loss of the limbic mineralocorticoid receptor impairs behavioral plasticity. Proc Natl Acad Sci U.S.A. 2006; 103: 195-200.

36. Freeman AI, Munn HL, Lyons V, Dammermann A, Seckl JR, Chapman KE. Glucocorticoid down-regulation of rat glucocorticoid receptor does not involve differential promoter regulation. J Endocrinol 2004; 183: 365-74.

37. Szuran TF, Pliska V, Pokorny J, Welzl H. Prenatal stress in rats: effects on plasma corticosterone, hippocampal glucocorticoid receptors, and maze performance. Physiol Behav 2000; 71: 353-62.

38. Mifsud KR, Saunderson EA, Spiers H, Carter SD, Trollope AF, Mill J, et al. Rapid down-regulation of glucocorticoid receptor gene expression in the dentate gyrus after acute stress in vivo: role of DNA methylation and microRNA activity. Neuroendocrinology 2017; 104: 157-69.

39. Herman JP, Spencer R. Regulation of hippocampal glucocorticoid receptor gene transcription and protein expression in vivo. J Neurosci 1998; 18: 7462-73.

40. Henry C, Kabbaj M, Simon H, Le Moal M, Maccari S. Prenatal stress increases the hypothalamo-pituitaryadrenal axis response in young and adult rats. J Neuroendocrinol 1994; 6: 341-5.

41. Harris A, Seckl J. Glucocorticoids, prenatal stress and the programming of disease. Horm Behav 2011; 59: 279-89. 